\title{
MICROPALAEONTOLOGY NOTEBOOK \\ Novel epifluorescence microscopy method to determine life position of foraminifera in sediments
}

\author{
JOAN M. BERNHARD \& SAMUEL S. BOWSER
}

Wadsworth Center, New York State Department of Health, PO Box 509, Albany, NY 12201-0509, USA.

\begin{abstract}
Microscopic examination of resin-embedded sediment cores has provided information regarding the sedimentary fabric in certain environments (e.g. Watling, 1988) as well as the in situ associations of rose Bengal-staincd infaunal foraminifera (c.g. Frankel, 1970, 1974). Unfortunately, difficulties connected with making and cxamining these resin-embedded cores have limited their widespread use in studying meioinfauna. In particular, sediment grains may obscure specimens when viewed by transmitted light microscopy. Also, using rose Bengal to identify live foraminifera can be problematic (Bernhard, 1988). Furthermore, fine-grained deposits are difficult to infiltrate with highly viscous embedding media (e.g. Epon $812 \geq 100$ centipoise), and may require a vacuum apparatus for proper infiltration (Watling, 1988).

Fluorescent probes were recently used to distinguish live from dead foraminifera (Bernhard ef al.. 1995). Here we report a novel method using an aldehyde-fixable fluorescent probe (Cell Tracker ${ }^{(\mathbb{N i n})}$ Green CMFDA) which, when viewed by epifluorescence microscopy, greatly enhances the visibility of biological material alive at the time of fixation. Cell Tracker Iind Green CMFDA is a membrane-permeant chloromethyl derivative of nuorescein diacet ate that is hydrolyzed by cellular esterases to yicld a membrane-impermeant, fluorescent intermediate which further undergoes a reaction with glutathione to form an aldehyde-fixable end-product (Haugland, 1992). We also used low viscosity embedding media (i.e. 20-60 centipoise) to facilitate infiltration. The method is applied to the study of live foraminifera in a sediment core.
\end{abstract}

\section{PROCEDURE}

A c. $1.5 \mathrm{~cm}$ diameter subcorer (fashioned from a $10 \mathrm{ml}$ syringe by removing the tip end, creating a cylinder into which two syringe plungers were inserted) was used to collect a subcore. While maintaining the subcore at ambient temperature, the top plunger was removed. The bottom plunger was replaced with polyester aquarium filter floss. The overlying seawater was withdrawn with a pipette, leaving approximately $\mathrm{i} \mathrm{cm}$ above the sediment. A solution containing the fluorogenic probe Cell Tracker Green CMFDA (Molecular Probes, Eugene, OR) was carefully added dropwise along the syringe barrel so that its final concentration was $1 \mu \mathrm{M}$. This solution was slowly perfused through the subcore until less than $c .1 \mathrm{~cm}$ of the solution remained above the sediment surface. A solution of $6 \%$ glutaraldehyde in $0.1 \mathrm{M}$ cacodylate buffer $(\mathrm{pH}$ 7.2) was next perfused through the subcore, followed by three perfusions with buffer. After the third buffer perfusion, the subcore was brought to room temperature and dehydrated by perfusing with a graded series of ethanol. After two perfusions with $100 \%$ ethanol, a 50:50 mixture of ethanol:catalyzed Ultra Low Viscosity Resin (Polysciences. Warrington. PA) was perfused through the subcore. and finally the subcore was infiltrated with $100 \%$ catalyzed resin and cured at $70^{\circ} \mathrm{C}$ for 12 hours. It can take as little as 24 hours from core acquisition to polymerization. To facilitate perfusion of compacted or fine-grained sediments. the bottom of the syringe barrel can be placed on an absorbent diaper to help draw the solutions through the subcore.

The polymerized subcore was cut into $\mathrm{c} .1 \mathrm{~mm}$ thick slices with a jeweller's saw and wet-polished with a graded series of waterproof silicon carbide sandpaper (c.g. DeLaca, 1986). Polished sections were mounted in mineral oil between a microscope slide and coverslip and examined with a microscope equipped with epifluorescence optics at fluorescein wavelengths. Foraminifera were often difficult to see in phase contrast (Fig. 1 A), but those that were alive at the time of fixation fluoresced brightly with epilfuorescence microscopy (Fig. 1B).

\section{APPLICATIONS}

Using this method, one can determine the distribution of foraminifera (and other live organisms) within sediments, as well as determine the extent and configuration of their pseudopodia. Present knowledge about the morphology and range of foraminiferal pseudopods is largely based on observations of networks
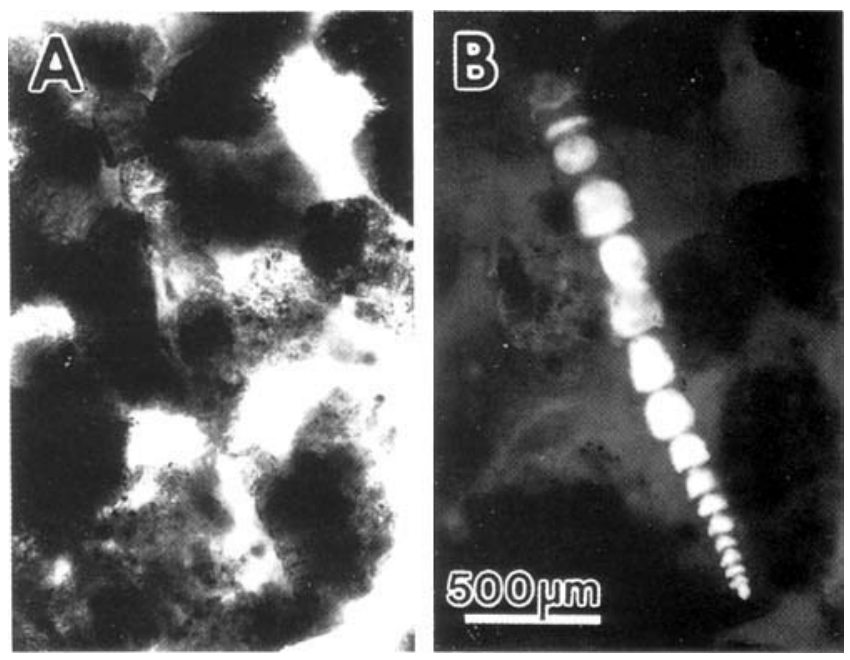

Fig. 1. (a) Phase-contrast micrograph of Leptohalysis scotti in sediments collected from $46 \mathrm{~m}$ water depth. Oslofjord, Norway. (b) Corresponding epifluorescence micrograph. Note that all chambers of the foraminifer fluoresce brighlly, indicating that cytoplasm is distribuled throughout the test.

deployed on glass slides (see Travis \& Bowser, 1991). The technique can also be used to assess the spatial relationships between a foraminifer and its food. metazoan structures (e.g. burrows), or prokaryotic constructs (e.g. biofilms). The method is currently being used on samples collected from laminated sediments containing Beggiatoa mats of the Santa Barbara Basin. and sandy sediments collected around Antarctica (Bernhard \& Bowser, in prep.).

\section{ACKNOWLEDGEMENTS}

We thank Elisabeth Alve (University of Oslo) for providing logisties for collection of samples used to test this procedurc. This work was supported by NSF grants OCE-9417097 to JMB and OPP-9220146 to SSB.

\section{Manuscript received August 1995 Manuscript accepted September 1995}

\section{Reference:}

Bernhard. J. M. 1988. Postmortem vital staining in benthic foraminifera: Duration and importance in population and distributional studies. Joumal of Foraminiferal Research, 18: $143-146$.

Bernhard. J. M. Newkirk, S.G. \& Bowser, S.S. 1995. Towards a non-lerminal viability assay for foraminiferan protists. Journal of Eukaryotic Microbiology , 42: 357-367.

DeLaca, T. E. 1986. The morphology and ecology of Astrammina rara. Jomrnal of Foraminiferal Resecirch, 16: 216-223.

Frankel, L. 1970. A lechnique for investigating microorganism associations. Joumal of Paleontology, 44: 575-577.

Frankel. L. 1974. Observations and speculations on the habitat and habits of Trochammina ochracea (Williamson) in subsurface sediments. Joumal of Paleontology', 48: 143-148.

Haugland, R. P. 1992. Handbook of Fluorescent Probes and Research Chemicals (5th Ed.). Molecular Probes. Eugene, OR.

Travis. J. L. \& Bowser. S. S. 1991. The motility of foraminifera. In Lee. J. J. \& Anderson. O. R. (Eds), Biology of the Foraminifera. 91-155. Academic Press. London.

Watling. L. 1988. Small-scale features of marine sediments and their importance to the study of deposit-feeding. Marine Ecology Progress Series, 47: 135-144. 